\title{
Major Increases between Pre- and Post-breakfast Glucose Levels May Predict Nocturnal Hypoglycemia in Type 2 Diabetes
}

\author{
Soichi Takeishi, Akihiro Mori, Miyuka Kawai, Yohei Yoshida, Hiroki Hachiya, \\ Takayuki Yumura, Shun Ito, Takashi Shibuya, Nobutoshi Fushimi, \\ Noritsugu Ohashi and Hiromi Kawai
}

\begin{abstract}
Objective The aim of this study was to determine whether nocturnal hypoglycemia may be predicted according to morning glucose levels.

Methods We retrospectively evaluated 106 patients with type 2 diabetes who underwent continuous glucose monitoring during admission. The pre-breakfast glucose level (Pre-breakfast level), highest postprandial glucose level within 3 hours after breakfast (Highest level), time from the start of breakfast to the highest postprandial glucose level (Highest time), difference between the pre-breakfast and highest postprandial breakfast glucose levels (Increase), area under the glucose curve ( $\geq 180 \mathrm{mg} / \mathrm{dL})$ within 3 hours after breakfast (Morning AUC), post-breakfast glucose gradient (Gradient), and the increase-to-pre-breakfast ratio (Increase/ Pre-breakfast) were calculated. The subjects were divided into hypoglycemic and non-hypoglycemic patients and compared for the above parameters using the $t$-test. A receiver operating characteristic analysis was used to determine the optimal cut-off values to predict nocturnal hypoglycemia (Hypoglycemia).

Results Twenty-eight patients (26.4\%) had hypoglycemia. The Pre-breakfast levels were significantly lower in patients with hypoglycemia than those without $(\mathrm{p}=0.03)$. The Increases were significantly higher in patients with hypoglycemia than those without $(\mathrm{p}=0.047)$. The Increase/Pre-breakfast ratio were significantly larger in patients with hypoglycemia than those without $(\mathrm{p}=0.0002)$. Their cut-off values were as follows (level, sensitivity, specificity, and area under the curve): $123 \mathrm{mg} / \mathrm{dL}, 0.89,0.55$, and $0.78(\mathrm{p}<0.0001) ; 90.5 \mathrm{mg} / \mathrm{dL}, 0.75$, 0.64 , and 0.76 ( $\mathrm{p}<0.0001)$; and $90.2 \%, 0.75,0.76$, and $0.78(\mathrm{p}<0.0001)$, respectively.
\end{abstract}

Conclusion Major increases between the pre- and post-breakfast glucose levels may predict nocturnal hypoglycemia in patients with type 2 diabetes.

Key words: nocturnal hypoglycemia, morning glucose increases, type 2 diabetes

(Intern Med 55: 2933-2938, 2016)

(DOI: 10.2169/internalmedicine.55.7085)

\section{Introduction}

Large clinical studies have shown that hypoglycemia is strongly associated with mortality in patients with diabetes mellitus (1-4). Although a relationship between nocturnal hypoglycemia and sudden death has been suggested (5), predicting nocturnal hypoglycemia is challenging in patients with type 2 diabetes, as many of these patients are unaware of their conditions, especially patients with advanced disease or elderly patients (6).

Nocturnal hypoglycemia has been suggested to be associated with not only major hyperglycemia in daytime $(7,8)$, but also increased morning glucose levels (9). Thus, clinical significance is high if morning glycemic variability can predict the presence of nocturnal hypoglycemia. However, the 


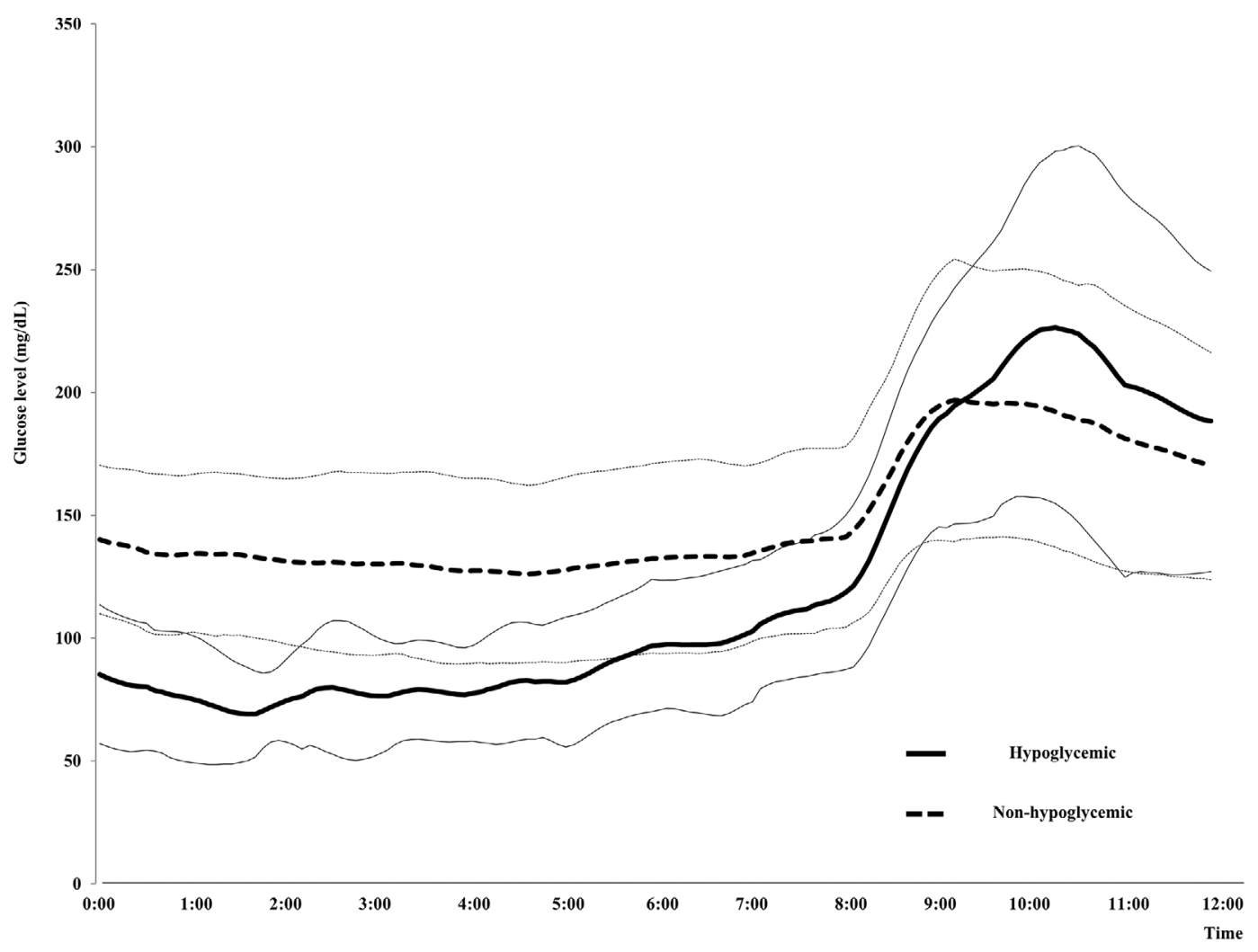

Figure 1. The graph indicates glycemic variability from nighttime to morning of continuous glucose monitoring in hypoglycemic patients $(p=28)$ or non-hypoglycemic patients $(p=78)$. Data are shown as the mean (thick lines) and standard deviation (fine lines).

mechanism of this relationship remains unknown. The Somogyi phenomenon $(10,11)$ is a cause of increased morning glucose levels. However, the dawn phenomenon $(11,12)$ can also cause increased morning glucose levels. Thus, an investigation based on continuous glucose monitoring from nighttime to morning is necessary to determine whether nocturnal hypoglycemia may be predicted based on morning glucose levels.

We therefore retrospectively studied whether nocturnal hypoglycemia may be predicted based on morning glucose levels in patients with type 2 diabetes using continuous glucose monitoring (13) (CGM) data.

\section{Materials and Methods}

\section{Study design and patient selection}

We retrospectively analyzed 106 patients with type 2 diabetes who underwent CGM during admission during a 2year period from 2013 to 2015. The study was approved by the institutional review board of Ichinomiyanishi Hospital, Japan. All of the patient data extracted were anonymized.

Patients who were aware of their hypoglycemia and took glucose tablets and those who had been taking $\alpha$ glucosidase inhibitors were excluded. We used CGM data measured with the Medtronic ipro2 device (Medtronic MiniMed, Northridge, USA). Nocturnal hypoglycemia was de- fined as a blood glucose level of $<70 \mathrm{mg} / \mathrm{dL}$ occurring from 0 am to $8 \mathrm{am}$. The subjects were also evaluated for the duration of nocturnal hypoglycemia.

\section{Outcomes and statistical analysis}

The parameters used as indices of glycemic variability included pre-breakfast glucose level (Pre-breakfast level), highest postprandial glucose level within 3 hours after breakfast (Highest level), time from the start of breakfast to the highest postprandial glucose level (Highest time), difference between pre-breakfast and highest postprandial breakfast glucose levels (Increase), area under the glucose curve ( $\geq 180 \mathrm{mg} / \mathrm{dL}$ ) within 3 hours after breakfast (Morning AUC), post-breakfast glucose gradient (Gradient), and the increased glucose level/pre-breakfast glucose level ratio (Increase/Pre-breakfast) (14).

The subjects were divided into hypoglycemic and nonhypoglycemic patients and compared for the above parameters using the $t$-test to examine whether the occurrence of nocturnal hypoglycemia may be predicted according to an analysis of these parameters. We analyzed the association between the patient characteristics [age, sex, duration of diabetes, body mass index (BMI), glycosylated hemoglobin (HbA1c) concentration, C-peptide index (CPI) and the presence of antidiabetic agents] and nocturnal hypoglycemia using a logistic regression analysis. A receiver operating characteristic (ROC) analysis was used to determine the optimal 
Table 1. Sample Characteristics and Parameters for Glycemic Variability Compared between Hypoglycemic and Non-hypoglycemic Patients.

\begin{tabular}{|c|c|c|c|c|}
\hline Characteristic & Overall & Hypoglycemic & Non-hypoglycemic & $\mathrm{p}$ \\
\hline $\mathrm{N}$ (Male / Female) & $106(56 / 50)$ & $28(11 / 17)$ & $78(45 / 33)$ & $\mathrm{p}_{2}=0.09$ \\
\hline Age, years & $66.6 \pm 11.0$ & $69.8 \pm 10.1$ & $65.5 \pm 11.2$ & $\mathrm{p}_{1}=0.07$ \\
\hline Duration of diabetes, years & $14.7 \pm 10.7$ & $15.9 \pm 11.4$ & $14.3 \pm 10.5$ & $\mathrm{p}_{1}=0.51$ \\
\hline BMI, $\mathrm{kg} / \mathrm{m}^{2}$ & $23.7 \pm 3.9$ & $22.7 \pm 2.9$ & $24.1 \pm 4.2$ & $\mathrm{p}_{1}=0.07$ \\
\hline HbAlc (NGSP), \% & $8.7 \pm 1.4$ & $8.9 \pm 1.7$ & $8.6 \pm 1.3$ & $\mathrm{p}_{1}=0.34$ \\
\hline $\mathrm{HbAlc}(\mathrm{IFCC}), \mathrm{mmol} / \mathrm{mol}$ & $71.2 \pm 15.6$ & $73.9 \pm 18.3$ & $70.2 \pm 14.6$ & $\mathrm{p}_{1}=0.34$ \\
\hline CPI & $1.0 \pm 0.8$ & $1.0 \pm 1.0$ & $1.0 \pm 0.7$ & $\mathrm{p}_{1}=0.87$ \\
\hline Total daily insulin dose, $\mathrm{U}$ & $21.1 \pm 16.3$ & $22.5 \pm 20.6$ & $20.4 \pm 14.0$ & $\mathrm{p}_{1}=0.65$ \\
\hline Basal insulin ratio, $\%$ & $75.7 \pm 26.5$ & $79.3 \pm 25.2$ & $74.0 \pm 27.1$ & $\mathrm{p}_{1}=0.42$ \\
\hline Nighttime duration of hypoglycemia, min & $51.7 \pm 89.7$ & $161.2 \pm 86.2$ & \multicolumn{2}{|c|}{$0 \pm 0 \mathrm{p}_{1}<0.0001$} \\
\hline Pre-breakfast glucose level, mg/dL & $128.7 \pm 33.8$ & $115.8 \pm 35.4$ & $133.4 \pm 39.1$ & $\mathrm{p}_{1}=0.03$ \\
\hline Highest glucose level, mg/dL & $226.4 \pm 62.7$ & $252.1 \pm 75.6$ & $217.2 \pm 55.6$ & $\mathrm{p}_{1}=0.03$ \\
\hline Highest glucose time, min & $100.8 \pm 42.2$ & $114.4 \pm 41.0$ & $96.0 \pm 41.7$ & $\mathrm{p}_{1}=0.047$ \\
\hline Increase glucose level, mg/dL & $97.7 \pm 56.3$ & $136.3 \pm 56.8$ & \multicolumn{2}{|c|}{$83.9 \pm 49.6 \mathrm{p}_{1}<0.0001$} \\
\hline AUC $(\geq 180 \mathrm{mg} / \mathrm{dL}), \mathrm{mg} \cdot \mathrm{min} / \mathrm{dL}$ & $7,027.4 \pm 9,268.6$ & $11,254.4 \pm 12,831.5$ & $5,510.0 \pm 7,112.1$ & $\mathrm{p}_{1}=0.03$ \\
\hline Glucose gradient, $\mathrm{mg} / \mathrm{dL} \cdot \min$ & $1.1 \pm 1.2$ & $1.3 \pm 0.5$ & $1.1 \pm 1.4$ & $\mathrm{p}_{1}=0.35$ \\
\hline Increase/Pre-breakfast, $\%$ & $85.4 \pm 62.5$ & $124.7 \pm 66.0$ & $71.3 \pm 57.4 \mathrm{p}$ & ${ }_{1}=0.0002$ \\
\hline Sulfonylurea agent, n (\%) & $10(9.4)$ & $2(7.1)$ & $8(10.3)$ & $\mathrm{p}_{2}=0.63$ \\
\hline Metformin, n (\%) & $68(64.2)$ & $16(57.1)$ & $52(66.7)$ & $\mathrm{p}_{2}=0.37$ \\
\hline Thiazolidinediones, n (\%) & $17(16.0)$ & $7(25.0)$ & $10(12.8)$ & $\mathrm{p}_{2}=0.13$ \\
\hline$\alpha$ - glucosidase inhibitor, $n(\%)$ & $0(0)$ & & & \\
\hline Insulin, $\mathrm{n}(\%)$ & $70(66.0)$ & $20(71.4)$ & $50(66.0)$ & $\mathrm{p}_{2}=0.48$ \\
\hline DPP-4 inhibitors, n (\%) & $58(54.7)$ & $19(67.9)$ & $39(50.0)$ & $\mathrm{p}_{2}=0.1$ \\
\hline GLP-1 receptor agonists, $\mathrm{n}(\%)$ & $13(12.3)$ & $5(17.9)$ & $8(10.3)$ & $\mathrm{p}_{2}=0.29$ \\
\hline Rapid-acting insulin secretagogue, n (\%) & $11(10.4)$ & $3(10.7)$ & $8(10.3)$ & $\mathrm{p}_{2}=0.95$ \\
\hline SGLT 2 inhibitor, n (\%) & $19(17.9)$ & $3(10.7)$ & $16(20.5)$ & $\mathrm{p}_{2}=0.25$ \\
\hline Insulin or sulfonylurea agent/Other agents & $76 / 30$ & $22 / 6$ & $54 / 24$ & $\mathrm{p}_{2}=0.35$ \\
\hline
\end{tabular}

Data are shown as the mean and standard deviation (SD). $\mathrm{p}_{1}$ : Welch's $t$-test, $\mathrm{p}_{2}$ : Chi-square test. BMI: body mass index, HbA1c: glycosylated hemoglobin, CPI: C-peptide index, Highest glucose level, highest postprandial glucose level within $3 \mathrm{~h}$ after breakfast; Highest glucose time, time from the start of breakfast to the highest postprandial glucose level; Increase glucose level, difference between pre-breakfast and highest postprandial breakfast glucose levels; AUC ( $\geq 180 \mathrm{mg} / \mathrm{dL})$, area under the glucose curve $(\geq 180 \mathrm{mg} / \mathrm{dL})$ within $3 \mathrm{~h}$ after breakfast; Glucose gradient, post-breakfast glucose gradient; Increase/Pre-breakfast, the increased glucose level/pre-breakfast glucose level ratio; Hypoglycemia, nocturnal hypoglycemia ( $<70 \mathrm{mg} / \mathrm{dL}$ occurring from 0 am to $8 \mathrm{am}$ ); DPP: dipeptidyl-peptidase, GLP: glucagon-like peptide, SGLT: sodium glucose co-transporter

cut-off values to predict nocturnal hypoglycemia (Hypoglycemia) (15). A p value $<0.05$ was considered to be statistically significant. Data are shown as the mean and standard deviation (SD).

\section{Results}

\section{Patient characteristics}

Fig. 1 shows glycemic variability from nighttime to morning of CGM in hypoglycemic patients $(n=28)$ and nonhypoglycemic patients $(n=78)$. Table 1 shows sample characteristics and parameters for glycemic variability compared between hypoglycemic and non-hypoglycemic patients. The study included 56 men and 50 women. The baseline characteristics included: mean age of $66.6 \pm 11.0$ years, body mass index of $23.7 \pm 3.9 \mathrm{~kg} / \mathrm{m}^{2}$, HbA1c level of $8.7 \pm 1.4 \%(71.2 \pm$ $15.6 \mathrm{mmol} / \mathrm{mol})$, duration of diabetes of $14.7 \pm 10.7$ years, and C-peptide index (= fasting C-peptide immunoreactivity/ FPG $\times 100)(\mathrm{CPI})$ of $1.0 \pm 0.8$. Seventy subjects received insulin therapy [basal-bolus insulin therapy $(n=27)$ or basal in- sulin therapy $(n=43)$ ] with long-acting insulin [insulin glargine $(n=37)$ or insulin degludec $(n=33)]$. Long-acting insulin was injected once at $8 \mathrm{am}$. The indices of glycemic variability were as follows: Pre-breakfast level, 128.7 \pm 33.8 $\mathrm{mg} / \mathrm{dL}$; Highest level, 226.4 $\pm 62.7 \mathrm{mg} / \mathrm{dL}$; Highest time, $100.8 \pm 42.2$ minutes; Increase, $97.7 \pm 56.3 \mathrm{mg} / \mathrm{dL}$; Morning AUC, 7,027.4 $\pm 9,268.6 \mathrm{mg} \cdot \mathrm{min} / \mathrm{dL}$; Gradient, $1.1 \pm 1.2 \mathrm{mg} / \mathrm{dL}$ -min; and the Increase/Pre-breakfast ratio, $85.4 \pm 62.5 \%$. Twenty-eight patients $(26.4 \%)$ had hypoglycemia. Hypoglycemic patients were shown to have nocturnal hypoglycemia lasting 161.2 \pm 86.2 minutes.

\section{Primary outcomes}

The Pre-breakfast levels were significantly lower among patients with hypoglycemia at $115.8 \pm 35.4 \mathrm{mg} / \mathrm{dL}$ compared to $133.4 \pm 39.1 \mathrm{mg} / \mathrm{dL}$ among those without $(\mathrm{p}=0.03)$. The Highest levels were significantly higher among patients with hypoglycemia at $252.1 \pm 75.6 \mathrm{mg} / \mathrm{dL}$ compared to $217.2 \pm 55.6$ $\mathrm{mg} / \mathrm{dL}$ among those without $(\mathrm{p}=0.03)$. The Highest times were significantly longer among patients with hypoglycemia at $114.4 \pm 41.0$ minutes compared to $96.0 \pm 41.7$ minutes 
Table 2. The Relationship between Sample Characteristics and Hypoglycemia.

\begin{tabular}{lrr}
\hline$(\mathrm{n}=106)$ & Hypoglycemia & \\
\hline Variable & OR $(95 \% \mathrm{CI})$ & $\mathrm{p}$ \\
\hline Age, years & $1.04(0.995-1.09)$ & 0.08 \\
Male sex, $\mathrm{n}$ & $0.47(0.20-1.15)$ & 0.1 \\
Duration of diabetes, years & $1.01(0.97-1.06)$ & 0.49 \\
BMI, kg/m ${ }^{2}$ & $0.91(0.81-1.03)$ & 0.13 \\
HbA1c (NGSP), \% & $1.18(0.87-1.59)$ & 0.28 \\
CPI & $1.05(0.61-1.81)$ & 0.85 \\
Total daily insulin dose, U & $1.01(0.98-1.04)$ & 0.6 \\
Basal insulin ratio, \% & $2.16(0.33-14.16)$ & 0.42 \\
Sulfonylurea agent, $\mathrm{n}$ & $0.67(0.13-3.38)$ & 0.63 \\
Metformin, $\mathrm{n}$ & $0.67(0.28-1.61)$ & 0.36 \\
Thiazolidinediones, $\mathrm{n}$ & $2.27(0.77-6.69)$ & 0.14 \\
Insulin, $\mathrm{n}$ & $1.40(0.55-3.59)$ & 0.48 \\
DPP-4 inhibitors, $\mathrm{n}$ & $2.11(0.85-5.24)$ & 0.11 \\
GLP-1 receptor agonists, $\mathrm{n}$ & $1.90(0.57-6.40)$ & 0.3 \\
Rapid-acting insulin secretagogue, $\mathrm{n}$ & $1.05(0.26-4.27)$ & 0.95 \\
SGLT 2 inhibitor, $\mathrm{n}$ & $0.47(0.12-1.74)$ & 0.25 \\
Insulin or Sulfonylurea agent, $\mathrm{n}$ & $1.63(0.59-4.53)$ & 0.35 \\
\hline
\end{tabular}

Data were analyzed using a univariate logistic regression analysis. OR: odds ratio, CI: confidence interval

among those without $(\mathrm{p}=0.047)$. The Increases were significantly higher among patients with hypoglycemia at $136.3 \pm$ $56.8 \mathrm{mg} / \mathrm{dL}$ compared to $83.9 \pm 49.6 \mathrm{mg} / \mathrm{dL}$ among those without $(\mathrm{p}=0.047)$. The Morning AUC were significantly larger among patients with hypoglycemia at 11,254.4 \pm $12,831.5 \mathrm{mg} \cdot \mathrm{min} / \mathrm{dL}$ compared to $5,510.0 \pm 7,112.1 \mathrm{mg} \cdot \mathrm{min} /$ $\mathrm{dL}$ among those without $(\mathrm{p}=0.03)$. The Increase/Prebreakfast ratio were significantly larger among patients with hypoglycemia at $124.7 \pm 66.0 \%$ compared to $71.3 \pm 57.4 \%$ among those without $(\mathrm{p}=0.0002)$. The Gradient was not significantly different between the two groups (Table 1).

According to a univariate analysis, the patient characteristics and use of antidiabetic agents were not associated with Hypoglycemia (Table 2).

In the subjects receiving insulin therapy, the total daily insulin dose and basal insulin ratio were not associated with Hypoglycemia. Insulin degludec (vs. insulin glargine) therapy was associated with Hypoglycemia (OR, 0.32; 95\% CI, $0.11-0.92 ; \mathrm{p}=0.03$ ).

Fig. 2 shows the ROC curves for hypoglycemia according to the indices of glycemic variability. Regarding the Prebreakfast glucose level, a cut-off value of $123 \mathrm{mg} / \mathrm{dL}$, which had the highest predictive ability, had a sensitivity of $89 \%$ and specificity of $55 \%$. The AUC for hypoglycemia was 0.78 (95\% CI 0.68-0.87, p<0.0001). Regarding Increase, a cut-off value of $90.5 \mathrm{mg} / \mathrm{dL}$, which had the highest predictive ability, had a sensitivity of $75 \%$ and specificity of $64 \%$. The AUC for hypoglycemia was 0.76 (95\% CI 0.65-0.86, $\mathrm{p}<0.0001)$. Regarding the Increase/Pre-breakfast ratio, a cutoff value of $90.2 \%$, which had the highest predictive ability, had a sensitivity of $75 \%$ and specificity of $76 \%$. The AUC for hypoglycemia was 0.78 (95\% CI 0.69-0.87, p<0.0001).

\section{Discussion}

A high risk of abnormal QT prolongation in the early morning in diabetic and non-diabetic patients with severe hypoglycemia has been reported (16). The relationships between hypoglycemia and abnormal QT prolongation, cardiac arrhythmia, and sudden death in patients with type 2 diabetes have been also reported (17). High risks of silent hypoglycemia and arrhythmias in patients with type 2 diabetes and cardiovascular diseases have been clarified (18). Thus, hypoglycemia in patients with type 2 diabetes may cause sudden death due to fatal arrhythmia, therefore hypoglycemia awareness is crucial. However, determining nocturnal hypoglycemia unawareness is difficult and often becomes problematic in everyday clinical practice (6).

On the other hand, hypoglycemia has been known to cause subsequent increases in the glucose level (Somogyi phenomenon) (19). Thus, if we evaluate patients with increased morning glucose levels in detail, we may detect patients who have nocturnal hypoglycemia. However, the causes of increased morning glucose levels are the effect of the dawn phenomenon (20) and increased glucose level after the first meal (breakfast) (21), as well as the Somogyi phenomenon, which are difficult to distinguish by merely measuring morning hyperglycemia. In fact, a previous report could not show the relationship between severe morning hyperglycemia and nocturnal hypoglycemia (22). Thus, we focused on not only morning hyperglycemia, but also glycemic variability from nighttime to morning using CGM. CGM allows for the detection of continuous glycemic variations and is useful to evaluate variability $(23,24)$. As a result, we suggest that nocturnal hypoglycemia may be predicted when pre-breakfast glucose levels are $<120 \mathrm{mg} / \mathrm{dL}$, glucose levels increase to $\geq 90 \mathrm{mg} / \mathrm{dL}$, and the Increase/Prebreakfast ratios are $\geq 90 \%$. This indicates that patients who have highly elevated morning glucose levels, despite rather low pre-breakfast glucose levels, are likely to have nocturnal hypoglycemia. The results of the ROC analysis in this study suggest that simple pre-breakfast glucose levels can predict nocturnal hypoglycemia to the same degree as increased glucose levels or Increase/Pre-breakfast ratios. Naturally, lower pre-breakfast glucose levels can greater predict nocturnal hypoglycemia. As a result, it is significant that the predictive abilities of increased glucose levels or Increased/Prebreakfast ratios are similar to the pre-breakfast glucose levels.

Although these results were analyzed using the CGM data, only two points can predict nocturnal hypoglycemia (pre- and post-breakfast levels). Therefore, it is possible to substitute the self-measurement of blood glucose (SMBG) for CGM. Determining nocturnal hypoglycemia unawareness by a 2-point SMBG is easy and useful with a high clinical significance. We consider that the Somogyi phenomenon is likely in patients with major increases between pre- and post-breakfast glucose levels, despite low pre-breakfast glu- 


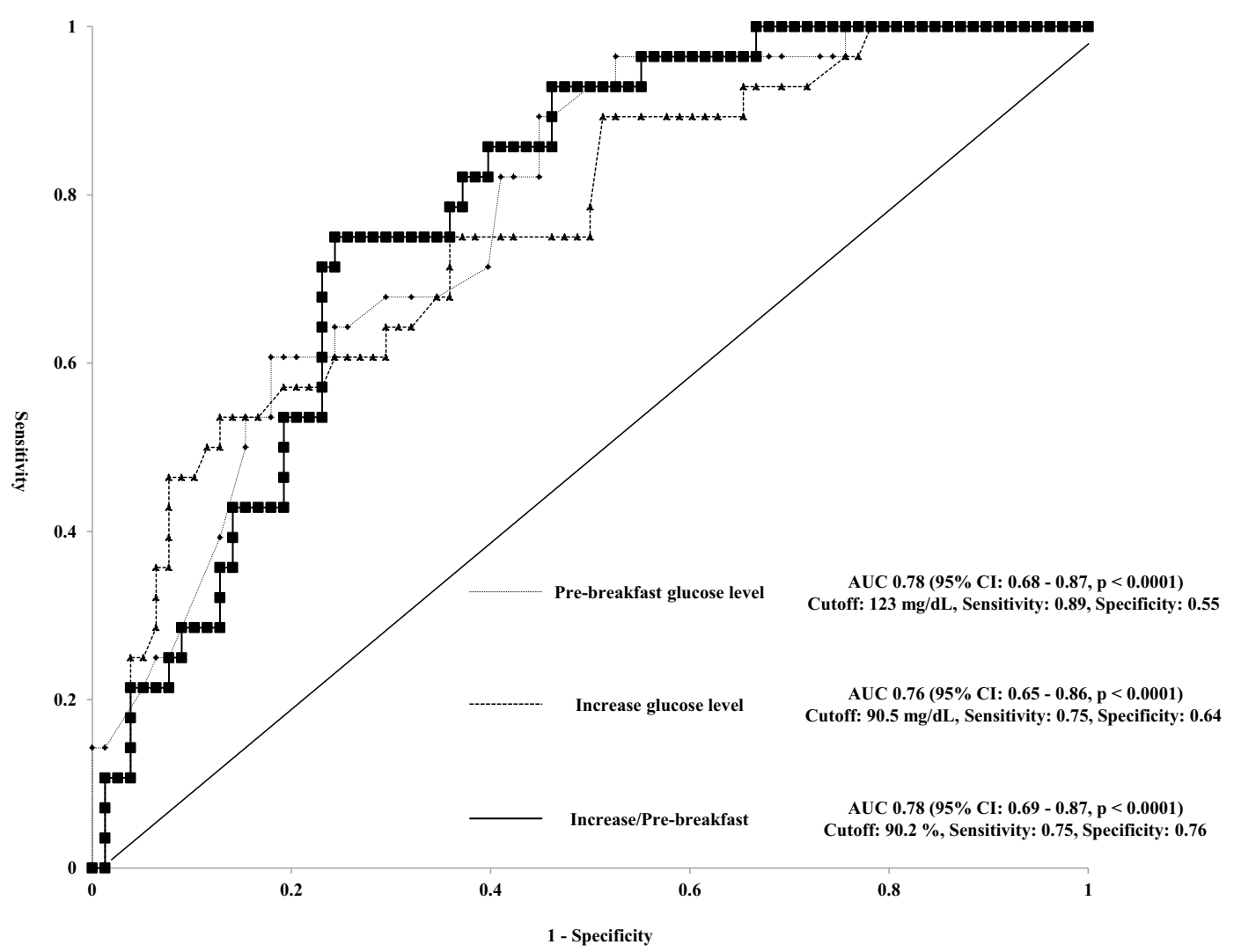

Figure 2. ROC curves for hypoglycemia in indices for glycemic variability. Pre-breakfast glucose level: The cut-off value of $123 \mathrm{mg} / \mathrm{dL}$, which had the highest predictive ability, had a sensitivity of $89 \%$ and specificity of $55 \%$. The AUC for hypoglycemia was 0.78 (95\% CI $0.68-0.87$, p<0.0001). Increase glucose level: The cut-off value of $90.5 \mathrm{mg} / \mathrm{dL}$, which had the highest predictive ability, had a sensitivity of $75 \%$ and specificity of $64 \%$. The AUC for hypoglycemia was 0.76 (95\% CI 0.65-0.86, $\mathbf{p}<\mathbf{0 . 0 0 0 1}$ ). Increase/Pre-breakfast: The cut-off value of $90.2 \%$, which had the highest predictive ability, had a sensitivity of $75 \%$ and specificity of $76 \%$. The AUC for hypoglycemia was 0.78 (95\% CI 0.69-0.87, p<0.0001). ROC: receiver operating characteristic, AUC: area under the curve, CI: confidence interval, Increase glucose level, difference between pre-breakfast and highest postprandial breakfast glucose levels; Increase/Pre-breakfast, the increased glucose level/pre-breakfast glucose level ratio.

cose levels. In this case, we consider that treatments should be adjusted in order to reduce nocturnal hypoglycemia.

This study showed that major increases between pre- and post-breakfast glucose levels may predict nocturnal hypoglycemia in patients with type 2 diabetes. However, this study was conducted retrospectively and the antidiabetic agents used in this study were not standardized (sulfonylurea agent or insulin were used). Hence, the validity of these results must be evaluated in a prospective study where the use of antidiabetic agents is standardized.

The authors state that they have no Conflict of Interest (COI).

\section{Financial Support}

This work was supported in part by Ichinomiyanishi Hospital.

\section{Acknowledgement}

Parts of this study were presented in oral presentation form at the 7th AASD Scientific Meeting and Annual Scientific Meeting of the Hong Kong Society of Endocrinology, Metabolism and Reproduction, November 21 and 22, 2015.

\section{References}

1. Zoungas S, Patel A, Chalmers J, et al. Severe hypoglycemia and risks of vascular events and death. N Engl J Med 363: 1410-1418, 2010.

2. Currie JC, Peters RJ, Tynan A, et al. Survival as a function of $\mathrm{HbA1c}$ in people with type 2 diabetes: a retrospective cohort study. Lancet 375: 481-489, 2010.

3. Turchin A, Matheny ME, Shubina M, Scanlon JV, Greenwood B, Pendergrass ML. Hypoglycemia and clinical outcomes in patients with diabetes hospitalized in the general ward. Diabetes Care 32: 1153-1157, 2009.

4. Takeishi S, Mori A, Hachiya H, et al. Hypoglycemia and glycemic variability are associated with mortality in non-intensive care unit hospitalized infectious disease patients with diabetes mellitus. J Diabetes Investig 7: 429-435, 2016.

5. Tsujimoto T, Yamamoto-Honda R, Kajio H, et al. Vital signs, QT prolongation, and newly diagnosed cardiovascular disease during severe hypoglycemia in type 1 and type 2 diabetic patients. Diabe- 
tes Care 37: 217-225, 2014.

6. Bremer JP, Jauch-Chara K, Hallschmid M, Schmid S, Schultes B. Hypoglycemia unawareness in older compared with middle-aged patients with type 2 diabetes. Diabetes Care 32: 1196-1198, 2009.

7. Hirsch IB, Smith LJ, Havlin CE, Shah SD, Clutter WE, Cryer PE. Failure of nocturnal hypoglycemia to cause daytime hyperglycemia in patients with IDDM. Diabetes Care 13: 133-142, 1990.

8. Lerman IG, Wolfsdorf JI. Relationship of nocturnal hypoglycemia to daytime glycemia in IDDM. Diabetes Care 11: 636-642, 1988.

9. Schmidt MI, Hadji-Georgopoulos A, Rendell M, Margolis S, Kowarski A. The dawn phenomenon, an early morning glucose rise: implications for diabetic intraday blood glucose variation. Diabetes Care 4: 579-585, 1981.

10. Stephenson JM, Schernthaner G. Dawn phenomenon and Somogyi effect in IDDM. Diabetes Care 12: 245-251, 1989.

11. Rybicka M, Krysiak R, Okopień B. The dawn phenomenon and the Somogyi effect: two phenomena of morning hyperglycaemia. Endokrynol Pol 62: 276-284, 2011.

12. Monnier L, Colette C, Dejager S, Owens D. Magnitude of the dawn phenomenon and its impact on the overall glucose exposure in type 2 diabetes: is this of concern? Diabetes Care 36: 40574062, 2013.

13. Leinung M, Thompson S, Nardacci E. Benefits of continuous glucose monitor use in clinical practice. Endocr Pract 16: 371-375, 2010.

14. Sakamoto $M$, Nishimura $R$, Irako $T$, Tsujino $D$, Ando $K$, Utsunomiya K. Comparison of vildagliptin twice daily vs. sitagliptin once daily using continuous glucose monitoring (CGM): crossover pilot study (J-VICTORIA study). Cardiovasc Diabetol 11: 92, 2012.

15. Mitsuishi S, Nishimura R, Ando K, Tsujino D, Utsunomiya $K$. Can fasting glucose levels or post-breakfast glucose fluctuations predict the occurrence of nocturnal asymptomatic hypoglycemia in type 1 diabetic patients receiving basal-bolus insulin therapy with long-acting insulin? PLoS One 10: e0144041, 2015.
16. Tsujimoto T, Yamamoto-Honda R, Kajio H, et al. High risk of abnormal QT prolongation in the early morning in diabetic and nondiabetic patients with severe hypoglycemia. Ann Med 47: 238-244, 2015.

17. Hanefeld M, Ganz X, Nolte C. Hypoglycemia and cardiac arrhythmia in patients with diabetes mellitus type 2. Herz 39: 312-319, 2014 (in German, Abstract in English).

18. Stahn A, Pistrosch F, Ganz X, et al. Relationship between hypoglycemic episodes and ventricular arrhythmias in patients with type 2 diabetes and cardiovascular diseases: silent hypoglycemias and silent arrhythmias. Diabetes Care 37: 516-520, 2014.

19. Bolli GB, Perriello G, Fanelli CG, De Feo P. Nocturnal blood glucose control in type I diabetes mellitus. Diabetes Care 16: 71-89, 1993.

20. Monnier L, Colette C, Sardinoux M, Baptista G, Regnier-Zerbib A, Owens D. Frequency and severity of the dawn phenomenon in type 2 diabetes: relationship to age. Diabetes Care 35: 2597-2599, 2012.

21. Jovanovic A, Gerrard J, Taylor R. The second-meal phenomenon in type 2 diabetes. Diabetes Care 32: 1199-1201, 2009.

22. Havlin CE, Cryer PE. Nocturnal hypoglycemia does not commonly result in major morning hyperglycemia in patients with diabetes mellitus. Diabetes Care 10: 141-147, 1987.

23. Klonoff DC. Continuous glucose monitoring continuous glucose monitoring: roadmap for 21 st century diabetes therapy. Diabetes Care 28: 1231-1239, 2005.

24. Takeishi S, Mori A, Fushimi N, et al. Evaluation of safety of insulin degludec on undergoing total-colonoscopy using continuous glucose monitoring. J Diabetes Investig 7: 374-380, 2016.

The Internal Medicine is an Open Access article distributed under the Creative Commons Attribution-NonCommercial-NoDerivatives 4.0 International License. To view the details of this license, please visit (https://creativecommons.org/licenses/ by-nc-nd/4.0/).

(C) 2016 The Japanese Society of Internal Medicine http://www.naika.or.jp/imonline/index.html 